\title{
Predicting Cancer from Depression: A Systematic Review of Prospective Studies
}

\author{
Deepa K Damodaran ${ }^{1}$, Varghese Paul $\mathrm{K}^{2}$
}

\section{ABSTRACT}

Past research has proposed depression as a risk factor for developing cancer. Because results of previous prospective epidemiological investigations are found to be conflicting and inconclusive, the current review evaluates the substantiation of cancer resulting from depression by reviewing prospective cohort studies. Identified studies, through a sensitive search strategy with the help of keywords, from Medline and Embase were retrieved as per the developed protocol and the PRISMA 2009 recommendations. The screening for the relevance of studies and the entire process of selection was done with criteria. A validated checklist ensured methodological quality whereas accuracy was made certain by double-data extraction technique. Results suggest a possible causal link between depression and the risk of cancer. When chronic and severe depression predicted greater risk of cancer, findings are inconclusive on the link between less severe depression and cancer. With the high prevalence of mood disorders, this review draws the attention towards a common biological pathway linking depression and cancer. This also highlights the necessity to discover means to control it, and hints the toxic effect of depression on risk factors in elevating the risk of cancer. Research and clinical implications are also dealt.

Keywords: Adverse childhood experiences, Stress, Progressive muscle relaxation, Adolescence, Stressors, Mental health

Our body and mind are interacting each other and it is thought to be true in case of development of cancer. Since the time of ancient Greeks it has been postulated that depression and cancer are linked (Snow, 1893). It is learnt that mental disorders such as depression and anxiety increases the risk of cancer. Many have attempted to explore the link between depression and cancer and these have produced both mixed and controversial findings (Hahn \& Petitti, 1988; Kaplan \& Reynolds, 1988; Zonderman, Costa, \& McCrae, 1989; Friedman, 1994; Chen \& Lin, 2011). A few meta-analyses suggested a small and marginally significant association between depression

\footnotetext{
${ }^{1}$ Research Scholar, Research and Development Centre, Bharathiar University, Coimbatore, Tamilnadu, India

${ }^{2}$ Head, Department of Psychology, Prajyoti Niketan College, Pudukad, Thrissur, Kerala, India

*Responding Author

Received: February 27, 2017; Revision Received: March 27, 2017; Accepted: March 29, 2017

(C) 2017 Damodaran D, Paul V; licensee IJIP. This is an Open Access Research distributed under the terms of the Creative Commons Attribution License (www.creativecommons.org/licenses/by/2.0), which permits unrestricted use, distribution, and reproduction in any Medium, provided the original work is properly cited.
} 
and subsequent cancer risk (Oerlemans, van den Akker, Schuurman, Kellen, \& Buntinx, 2007; McGee, Williams, \& Elwood, 1994). As this is inconclusive, the present study focuses on the findings of prospective studies that were published later. The objective of the current study was to appraise the substantiation for predicting cancer from depression among adults through the review of prospective cohort studies.

\section{METHODOLOGY}

The review was based on a plan that was developed in advance after consulting experts, the general recommendations from the PRISMA 2009 revision (Moher, Liberati, Tetzlaff, \& Altman, 2009) in relation to processing and reporting of results, and pre-defined, documented inclusion criteria.

\section{Inclusion and Exclusion criteria}

The first level in the selection process was a relevance screen that the study: a) is related directly to "depression" and "cancer risk"; b) was a primary study (not a review of studies); c) is the research involved only human subjects; and d) has a follow-up period of 7 years or more. The next step assessed prospective cohort studies for meeting the following inclusion criteria: the study (1) is general population based, original empirical research published in a peer-reviewed journal of English language, (2) focused on prediction of cancer from depression, (3) reported measurement of depression using standardized scales, and (4) reported RR and CI. Studies focusing on pediatric or adolescent population, studies considering depression as an outcome of cancer, ascertainment of depression from self reports alone, and studies without empirical data were excluded. The main exclusion criterion was the period of less than 7 years between the collection of exposure data and assessment of the last reported outcome data.

\section{Literature search}

Studies included in the current review were identified from electronic databases, by checking reference lists of articles for additional relevant publications, and by consulting experts in the relevant field. Medline and Embase from 1996 December to August 2010 were searched using a sensitive search strategy with keywords such as "depress*" in addition to "cancer risk". The search was limited to articles published in English language as full text reports only. The last search was run on 19 September 2012. Searches were independently performed by two researchers.

\section{Selection of studies}

Among a total of 191 investigations that were recognized for addition in the current review, 179 were from Medline and Embase databases and 12 studies were from other sources. Of the remaining studies (184) that were found after removing duplicated ones, 133 were further avoided because these could not meet the current study criteria. Three more were found to be not useful since full text of the article was not accessible. On detailed examination of the full text of 
the remaining 48 citations, 45 studies were excluded for not meeting the inclusion criteria. Remaining 3 studies were considered for the review. There were no unpublished relevant studies that could be obtained. All investigations under final review were prospective cohorts published in English language. Out of 48 studies, 3 articles indicated substantiation of a connection between depression and the risk of cancer.

\section{Data extraction and Assessment of Quality}

The full-text article or abstract of any investigation that seemed to fulfill the inclusion criteria was retrieved for detailed review. Two investigators, who were masked to the journals, reviewed and individually appraised articles for suitability. Differences in opinion between reviewers were solved through discussion. A data extraction sheet developed and refined after consulting experts was used to retrieve necessary information. Information was extracted from each included study consisted of details such as its publication, country where the study was conducted, age of participants, methodological aspects including the sample size, the design, key variables (exposures, outcomes, and confounding factors, including how these were measured), length of the follow-up, statistical techniques used, and results. Data were extracted by two reviewers separately and made it in to two separate Excel documents. This double data extraction method ensured more accuracy. Files were, then, compared and when data did not match, the original article was re-checked. Criteria used for quality assessment are given in table.1.

Table. 1. Predicting cancer from depression: Criteria for Quality Assessment

\begin{tabular}{|l|l|}
\hline SN & \multicolumn{1}{|c|}{ Criteria } \\
\hline 1. & $\begin{array}{l}\text { Representativeness of the population } \\
\text { Population-based representative }=1 \\
\text { Not representative, or no description }=0\end{array}$ \\
\hline 2. & $\begin{array}{l}\text { Assessment of depression } \\
\text { Secure hospital record/ using standardized scale }=1 \\
\text { Self-reported or structured interview or self-administered non }- \text { standardized scale or no } \\
\text { description = 0 }\end{array}$ \\
\hline 3. & $\begin{array}{l}\text { Ascertainment of exposure of interest } \\
\text { Data on depression collected prospectively }=1 \\
\text { Data on depression collected retrospectively =0 }\end{array}$ \\
\hline 4. & $\begin{array}{l}\text { Assessment of outcome (cancer) } \\
\text { Use of hospitalization records/ /National death index/ National cancer registry =1 } \\
\text { Self-reported or structured interview or self-administered questionnaire or no description }=0\end{array}$ \\
\hline 5. & $\begin{array}{l}\text { Appropriate methods to control confounding } \\
\text { Yes = 1 (multiple variables adjusted) } \\
\text { No = 0 (univariate analysis or controls for age/sex only) }\end{array}$ \\
\hline 6. & $\begin{array}{l}\text { Adequacy of follow-up of cohorts or response rate } \\
\text { Completeness good (>80\%), with description of those lost to follow-up = 1 } \\
\text { Completeness poor ( } \leq 80 \% \text { ) or no statement =0 }\end{array}$ \\
\hline
\end{tabular}

(C) The International Journal of Indian Psychology, ISSN 2348-5396 (e) | ISSN: 2349-3429 (p) | 
Predicting Cancer from Depression: A Systematic Review of Prospective Studies

\begin{tabular}{|l|l|}
\hline SN & \multicolumn{1}{|c|}{ Criteria } \\
\hline 7. & $\begin{array}{l}\text { Appropriate statistical analysis } \\
\text { Yes }=1 \\
\text { No }=0\end{array}$ \\
\hline 8. & $\begin{array}{l}\text { Source of funding declared } \\
\text { Yes (financial disclosure, funding/support/grant declared) }=1 \\
\text { No }=0\end{array}$ \\
\hline
\end{tabular}

\section{RESULTS}

The majority of studies (Gross, Gallo, \& Eaton, 2010; Penninx, et al., 1998) were from USA and one study was from Europe (Knekt, et al., 1996). All studies provided information from regional or nationally representative samples. Descriptive characteristics of the selected studies are presented in table.2.

Table.2. Descriptive characteristics of the selected studies $N=3$

\begin{tabular}{|l|l|l|l|l|l|l|l|}
\hline $\begin{array}{l}\text { First } \\
\text { author }\end{array}$ & Quality & $\begin{array}{l}\text { Total } \\
\text { sample } \\
(\% \\
\text { women) }\end{array}$ & $\begin{array}{l}\text { Setting of } \\
\text { cohort }\end{array}$ & $\begin{array}{l}\text { Age } \\
\text { Range } \\
\text { (Years) }\end{array}$ & $\begin{array}{l}\text { Depression } \\
\text { questionnaire }\end{array}$ & $\begin{array}{l}\text { Diagnosis } \\
\text { (Data } \\
\text { collection } \\
\text { source) }\end{array}$ & $\begin{array}{l}\text { Length of } \\
\text { follow-up, } \\
\text { number } \\
\text { and/or } \\
\text { times of } \\
\text { follow-up } \\
\text { measurem- } \\
\text { ents }\end{array}$ \\
\hline $\begin{array}{l}\text { Gross } \\
(2010)\end{array}$ & High & 3177 & $\begin{array}{l}\text { Population } \\
\text { sample, } \\
\text { cancer- } \\
\text { free } \\
\text { subjects }\end{array}$ & $\begin{array}{l}\text { aged } \\
18 \text { and } \\
\text { older }\end{array}$ & $\begin{array}{l}\text { Diagnostic } \\
\text { Interview } \\
\text { Schedule } \\
\text { (DIS) }\end{array}$ & $\begin{array}{l}\text { Self reports } \\
\text { and death } \\
\text { certification }\end{array}$ & $\begin{array}{l}\text { years, } \\
\text { 3 times }\end{array}$ \\
\hline $\begin{array}{l}\text { Penninx } \\
(1998)\end{array}$ & High & $\begin{array}{l}4825 \\
(64.6)\end{array}$ & $\begin{array}{l}\text { Population } \\
\text { sample, } \\
\text { cancer- } \\
\text { free } \\
\text { subjects }\end{array}$ & $71-96$ & $\begin{array}{l}\text { Center for } \\
\text { Epidemiologic } \\
\text { Studies- } \\
\text { Depression } \\
\text { (CES-D) scale }\end{array}$ & $\begin{array}{l}\text { Hospitaliza- } \\
\text { tion } \\
\text { records and } \\
\text { death } \\
\text { certificate }\end{array}$ & $\begin{array}{l}\text { 7 years } \\
\text { Not } \\
\text { specified }\end{array}$ \\
\hline $\begin{array}{l}\text { Knekt } \\
(1996)\end{array}$ & High & $\begin{array}{l}7,018 \\
(55)\end{array}$ & $\begin{array}{l}\text { Population } \\
\text { sample, } \\
\text { cancer- } \\
\text { free } \\
\text { subjects }\end{array}$ & $30-95$ & $\begin{array}{l}\text { Present State } \\
\text { Examination } \\
\text { (PSE) }\end{array}$ & $\begin{array}{l}\text { Cancer } \\
\text { registry }\end{array}$ & $\begin{array}{l}\text { 14 years } \\
\text { Not } \\
\text { specified }\end{array}$ \\
\hline
\end{tabular}

Included studies provided 15020 participants for the current review. The main inclusion criteria entailed cancer free adults who have depression at the time of study entry. Cancer-free subjects only were eligible for follow-up. When two studies (Gross, et al., 2010; Knekt, et al., 1996) had a wide range of ages included, one study (Penninx, et al. 1998) had subjects aged 71 years and older only. Duration of follow-up ranged from 7 (Penninx, et al., 1998) to 24 (Gross, et al., 2010)

(c) The International Journal of Indian Psychology, ISSN 2348-5396 (e)| ISSN: 2349-3429 (p) | 198 
years. Whereas Gross, et al. reported the measurement of incidence of cancer during three follow up interviews (at 1 year, 12 year and 11 year) and also from the National Death Index, other studies (Penninx, et al. 1998; Knekt, et al., 1996) had not specified follow-up measurements but had specified sources such as Cancer registry, Death certificate and hospitalization records.

\section{Definition and Operationalization of 'Depression'}

Authors had not offered a theoretical definition for their concept of "depression". The term for "chronic depression" was operationalized (Penninx, et al., 1998) for its presence when the number of depressive symptoms exceeded a specific cut off point on Center for Epidemiologic Studies-Depression (CES-D) scale at baseline (Table. 3). Respondents were referred to as persons with chronically and non-chronically depressed mood in one study (Penninx, et al.1998) and in another study, three mutually exclusive groups were identified by quantifying depression status as a lifetime history of major depression, a lifetime history of a dysphoric episode, or neither a history of major depression nor dysphoric episode (Gross, et al., 2010). Depressiveness score based on items of the 36-item General Health Questionnaire was categorized in one study (Knekt, et al., 1996). Gross, et al. applied Diagnostic Interview Schedule (DIS) (standardized, interviewer-administered tool) which is composed of standardized questions to measure symptoms, co-occurrence of symptoms in time, and other important factors, whereas another study (Penninx, et al., 1998) used the CES-D scale to determine the primary exposure of interest. Both scales were useful to make DSM-III diagnoses of depression. The third study (Knekt, et al., 1996) applied the Present State Examination (PSE), a standardized psychiatric interview schedule.

\section{Relationship between Depression and overall Cancer}

Out of 3 articles selected, 2 studies examined the connection between depression and over all cancer (Table. 3).

Table. 3. Predicting cancer from Depression: outcome measures in selected studies $N=3$

\begin{tabular}{|l|l|l|l|l|}
\hline Cohort & $\begin{array}{l}\text { Number of total } \\
\text { cancer patients } \\
\text { (\% on total) and } \\
\text { cancer status }\end{array}$ & Cancer -Definition & Statistical test & $\begin{array}{l}\text { Results } \\
\text { (adjusted) } \\
\text { reported in } \\
\text { paper }\end{array}$ \\
\hline $\begin{array}{l}\text { Gross } \\
(2010)\end{array}$ & $\begin{array}{l}334 \text { cancer cases } \\
(10.51 \%) \\
\text { Sites: } \\
\text { breast, colon, } \\
\text { lung, prostate, } \\
\text { and skin cancers }\end{array}$ & $\begin{array}{l}\text { Participants reports of a history } \\
\text { of cancer; Cancer was } \\
\text { considered present if it was } \\
\text { either a primary or contributing } \\
\text { cause of death on a death } \\
\text { certificate. }\end{array}$ & $\begin{array}{l}\text { Cox } \\
\text { proportional } \\
\text { hazards model } \\
\text { (95\% CI: } \\
1.2,3.0)\end{array}$ \\
\hline $\begin{array}{l}\text { Penninx } \\
(1998)\end{array}$ & $\begin{array}{l}402 \text { cancer cases } \\
(8.33 \%)\end{array}$ & $\begin{array}{l}\text { Any listed hospital discharge } \\
\text { diagnosis or underlying cause } \\
\text { of death with ICD-9 codes } \\
\text { Sites: } \\
\text { colon, prostate, }\end{array}$ & $\begin{array}{l}\text { Cox } \\
\text { proportional } \\
\text { hazards model }\end{array}$ & $\begin{array}{l}1.88 \\
(95 \% \text { CI: } \\
1.13-3.14) .\end{array}$ \\
\hline
\end{tabular}

(c) The International Journal of Indian Psychology, ISSN 2348-5396 (e)| ISSN: 2349-3429 (p) | 199 
Predicting Cancer from Depression: A Systematic Review of Prospective Studies

\begin{tabular}{|l|l|l|l|l|}
\hline & $\begin{array}{l}\text { lymphatic and } \\
\text { hematopoietic } \\
\text { organs urinary } \\
\text { tract, and breast }\end{array}$ & $\begin{array}{l}\text { event that occurred during } \\
\text { follow- up was used as a } \\
\text { primary end point. }\end{array}$ & & \\
\hline $\begin{array}{l}\text { Knekt } \\
(1996)\end{array}$ & $\begin{array}{l}605 \\
(8.6 \%) \\
\text { Sites: } \\
\text { All sites, Lung, } \\
\text { breast }\end{array}$ & Based on Cancer registry. & $\begin{array}{l}\text { Cox } \\
\text { proportional } \\
\text { hazards model }\end{array}$ & $\begin{array}{l}\text { (95\% CI: } \\
0.68-1.14) .\end{array}$ \\
\hline
\end{tabular}

The primary outcome assessed was the incidence of cancer after baseline assessment in relation to depression. When one study (Gross, et al., 2010) focused on the relationship between depression and incident cancer focusing on subtypes of cancer, another one (Penninx, et al., 1998) investigated whether high level of depressive symptoms when present for a longer duration is linked with greater risk of cancer. The relation between depressiveness and later incidence of lung cancer was focused in the third study (Knekt, et al., 1996). While Gross et al., found a significant association between depression and overall cancer, other two studies (Penninx, et al., 1998; Knekt, et al., 1996) reported non significant association with baseline depressed mood. But the risk was higher when the individual had long-term depressive symptoms (Penninx, et al., 1998). Heterogeneity was seen in outcome measures which might have been due to methodological differences. Thus, although chronic depression is learnt to be linked with elevated cancer risk, findings on association between less severe depressive episodes and cancer risk were not conclusive.

\section{Links between depression and subtypes of cancer}

Analysis for subtype-specific cancers was reported in all studies (Table 4.).

Table. 4. Predicting cancer from Depression: confounding factors adjusted for, mortality and secondary outcomes in selected studies $N=3$

\begin{tabular}{|l|l|l|l|}
\hline Cohort & Confounding variables & $\begin{array}{l}\text { Cancer } \\
\text { mortality } \\
(\%)\end{array}$ & $\begin{array}{l}\text { Results (adjusted) reported in } \\
\text { paper for breast cancer occurrence }\end{array}$ \\
\hline $\begin{array}{l}\text { Gross } \\
(2010)\end{array}$ & $\begin{array}{l}\text { Age, sex, race, marital status, H/o } \\
\text { alcohol abuse/ dependence, and } \\
\text { smoking, SES, parity when } \\
\text { considering hazards for breast } \\
\text { cancer. }\end{array}$ & $\begin{array}{l}\text { Not } \\
\text { specified }\end{array}$ & $\begin{array}{l}\text {-Breast cancer- 4.4 } \\
(95 \% \text { CI: 1.08, 17.6) } \\
\text { Women only. }\end{array}$ \\
\hline $\begin{array}{l}\text { Penninx } \\
(1998)\end{array}$ & $\begin{array}{l}\text { Age, sex, race, disability, hospital } \\
\text { admissions, alcohol intake, and } \\
\text { smoking, BMI, use of } \\
\text { antidepressants. }\end{array}$ & $11(7.5 \%)$ & $\begin{array}{l}\text {-Breast cancer-No depressed cases } \\
\text { of malignancy } \\
\text {-Lung cancer -2.10 } \\
\text { (95\% CI: 0.49-8.92) } \\
\text {-Colon cancer - 1.37 }\end{array}$ \\
\hline
\end{tabular}

(c) The International Journal of Indian Psychology, ISSN 2348-5396 (e)| ISSN: 2349-3429 (p) | 200 
Predicting Cancer from Depression: A Systematic Review of Prospective Studies

\begin{tabular}{|l|l|l|l|}
\hline & & & $\begin{array}{l}\text { (95\% CI: } 0.33-5.74) \\
\text {-Prostate cancer }-1.47 \\
\text { (95\% CI: } 1.01-22.79)\end{array}$ \\
\hline $\begin{array}{l}\text { Knekt } \\
(1996)\end{array}$ & Age, sex & Not & -Breast cancer-1.96 \\
& & specified & $\begin{array}{l}\text { (95\% CI: } 0.88-4.33) \\
\text {-Lung cancer- } 1.65 \\
\text { (95\% CI: } 0.60-4.58) \text { only males }\end{array}$ \\
\hline
\end{tabular}

Gross, et al., (2010) investigated on the relationship between depression and incident cancer focusing on subtypes of cancer whereas another study (Knekt, et al., 1996) specifically investigated on the association between depressiveness and subsequent incidence of lung cancer as the primary outcome of interest. Yet another study examined it as the secondary outcome (Penninx, et al., 1998). When one study (Penninx, et al., 1998) reported consistent relationship between chronic depression and most types of cancer, another study uncovered excess risk associated with major depression and breast cancer (Gross, et al., 2010). While excess risk of lung cancer (Knekt, et al., 1996) was associated with high depressiveness in one study, there was no significant association found in another investigation (Gross, et al., 2010). Relative risks estimated in majority of investigations were based on very small number of individuals with depression. Non significant associations were reported between depression and cancers of prostate, colon (Gross, et al., 2010; Penninx, et al., 1998), skin (Gross, et al., 2010) lymphatic and hematopoietic organs, and of the urinary tract. This heterogeneity in findings might have been due to methodological heterogeneity and also insufficient numbers of cancer cases to calculate several hazard ratios for site-specific cancer types, as reported by all three studies.

\section{Secondary outcome (Cancer mortality and association with mental disorders)}

Findings on secondary outcomes were not conclusive (Table 4.) as there was less number of studies and heterogeneity in methodology. The adjusted cancer mortality risk for chronically depressed mood was 2.22 (95\% CI: 4 1.19-4.16) as reported by Penninx, et al. (1998). Findings on association between other mental disorders and cancer (Gross, et al., 2010; Knekt, et al., 1996) were non-significant although one study (Knekt, et al., 1996) reported a significantly greater risk of lung cancer among men with psychosis.

\section{DISCUSSION}

Current review has attempted to systematically summarize results from 3 prospective studies ( $\mathrm{N}=$ $>100$ ) with $\geq 7$ years follow-up on association between depression and cancer. It hints a causal link between depression and cancer risk. Chronic nature and severity of depression seems to be the elements linking depression and later development of cancer. The association between less severe, short term depressive symptoms and site specific cancers is only suggestive possibly due to heterogeneity of cancer diagnoses and cancer types. Thus our findings remain suggestive but not proven. It is also found that there is simply not enough evidence to arrive a definite conclusion about cancer mortality and association with other mental disorders. It is likely that the

(C) The International Journal of Indian Psychology, ISSN 2348-5396 (e)| ISSN: 2349-3429 (p) | 201 
current review barred a few high-quality studies along with studies of poor-quality. However, prospective measurement of the exposure variable long before the outcome had occurred is strength of most of the included studies. But it would not have had high influence on the robustness of findings because studies under the review were a few. Included studies had methodological differences and they differed in characteristics of depression and cancer measurement also.

\section{Evidence from other studies}

Though the current findings are not very conclusive of the current review, it is consistent with findings from previous meta analyses which had proposed a tendency concerning a small and marginally significant association between depression and risk of cancer (Oerlemans, et al., 2007; McGee, et al., 1994). Chronic nature and severity seems to be the elements linking depression and later development of cancer. Investigations with longer duration of follow-up have shown stronger relationships specifically for subtypes of cancer with hormonally mediated pathologies e.g, breast cancer. Because most cancer types have long latent periods (Oerlemans, et al., 2007; McGee, et al., 1994).

\section{Mechanisms explaining association}

Depression can either have a long, delayed effect on the risk of cancer, or it may predominantly act along with other known risk factors to increase the risk of cancer. According to hypothalamic pituitary-adrenal (HPA) axis theory patients with depression are reported to have hyper secretion of the cortisol, adrenal hypertrophy, and an increased cortisol response to adrenocorticotropic hormone. Due to the immunoregulatory effects of adrenal corticosteroids there can be immunosuppressant (Miller, Spencer, McEwen \& Stein, 1993; Stein, Miller \& Trestman, 1991). Functions of the immune system are impaired by the individual's depressed mood and affect. This increases the risk for initiation or progression of cancer (Ader, Cohen \& Felten, 1995). Another probable reason may be that health risk behaviours (e.g., reduced physical activity, excessive alcohol intake, and disorders related to over-eating) which are risk factors of cancer may be more among depressed persons (Kabat \& Wynder, 1992; Lee \& Paffenbarger, 1992). Extant literature report that depressed smokers find it difficult to quit the habit (Anda, Williamson, Escobedo, Mast, Giovino \& Remington, 1990) instead, they inhale more deeply and smoke more cigarettes (Friedman, 1996) than nondepressed counterparts. It may also be that the age-specific vulnerability also predisposes a depressed individual to neoplastic disorders. Decreased motivation for surveillance of cancer among patients with depressed mood can not also be overlooked. Chronic depression remains largely under diagnosed and under treated in cancer patients. 


\section{Predicting Cancer from Depression: A Systematic Review of Prospective Studies}

\section{Strengths and limitations}

The initial search revealed that papers suitable for inclusion are widely scattered in journals of various disciplines. Though two studies had longer follow up periods the selected studies had several limitations that might have influenced the reliability of our findings. Gross, et al. (2010) had performed the sensitivity analysis thrice to test the robustness of findings and the study had longer follow-up times but differential follow-up, possibility of unaccounted important confounders, measurement of exposure variable with a relatively less sensitive tool, self-report as a data collection source for outcome measurement, methodological peculiarities e.g., not following the entire cohort to death or until a cancer onset, might have attenuated their findings. While the second study (Penninx, et al., 1998) had several points of measurement of depressive symptoms, it is limited by the short follow up period, analyses that included data for the first year also, the narrow age range of subjects, and the small number of chronically depressed persons. Lack of multiple follow-up times and changes of the psychometric properties of the depressiveness score during follow-up may also have affected findings of the third study (Knekt, et al., 1996). Cancer site-specific analyses were restricted on all studies by the limited number of cases.

The main limitation of the current review is limited number of included studies and lack of statistical analysis. Though the review had strengths of following PRISMA flow chart and executing a double data extraction technique, bias might have been introduced due to issues in the literature search. This may have led to leaving out any relevant article and also inaccuracies in the conversion of primary data. Second, due to time constraints, the current review focuses exclusively on published investigations. There is also a possibility for publication bias with positive results being reported and negative ones are not. Hence, the substantiation for an elevated risk of cancer in association with depression can be regarded as less sufficient and conclusions about the primary outcome of interest require more additional studies.

\section{Implications}

Findings that there can be a long delayed effect of depression which may increase the risk of cancer, or the interaction of depression with any of the known risk factors of cancer require further exploration. An investigation with a larger sample would enable statistical analysis and site specific cancer analysis. Future studies can focus on personality, health risk behaviors and other variables including anxiety to explain the depression-cancer relationship. Findings also draw attention from clinicians because depression influences the immune and hormonal systems of the body. Thus knowledge about the psychobiological mechanisms under which it operates becomes very crucial. Early detection of at risk individuals and appropriate interventions for protection from neoplastic disorders are very essential. 


\section{CONCLUSION}

In nut shell, individuals diagnosed with cancer are a client population with unique needs and demands. Though as such, any conclusion made may be moderated by the smaller number of investigations considered under this review, current study findings draw attention to a possible connection between depression and cancer. Thus it is necessary to widen the awareness regarding the relationship between depression and cancer. Viewed as a whole, results of the present investigation are supporting the hypothesis that depression increases cancer risk.

\section{Acknowledgments}

The author appreciates all those who participated in the study and helped to facilitate the research process.

Conflict of Interests: The author declared no conflict of interests.

\section{REFERENCES}

Ader, R., Cohen, N., \& Felten. D. (1995). Psychoneuroimmunology: interaction between the nervous system and the immune system. Lancet, 345, 99-103.

Anda, R. F., Williamson, D. F., Escobedo, L. G., Mast, E. E., Giovino, G. A., \& Remington, P. L. (1990). Depression and the dynamics of smoking. A national perspective. Journal of the American Medical Association, 264, 1541-1555.

Chen, Y. H., \& Lin, H. C. (2011). Increased risk of cancer subsequent to severe depression- a nationwide population -based study. Journal of Affective Disorders, 131 (1-3), 20002006. doi: 10.1016/j.jad.2010.12.006.

Friedman, G. D. (1994). Psychiatrically-diagnosed depression and subsequent cancer. Cancer Epidemiology, Biomarkers and Prevention, 3, 11-13.

Friedman, G. D. (1996). Depression, smoking, and lung cancer. American Journal of Epidemiology, 144, 1104-1106.

Gross, A. L., Gallo, J. J., \& Eaton, W.W. (2010). Depression and cancer risk: 24 years of followup of the Baltimore Epidemiologic Catchment Area sample. Cancer Causes Control, 21 (2), 191-199. doi:10.1007/s10552-009-9449-1.

Hahn, R. C. \& Petitti, D. B. (1988). Minnesota Multiphasic Personality Inventory-rated depression and the incidence of breast cancer. Cancer, 61, 845-848.

Kabat, G. C. \& Wynder, E. L. (1992). Body mass index and lung cancer risk. American Journal of Epidemiology, 135, 769-774.

Kaplan, G. A. \& Reynolds, P. (1988). Depression and cancer mortality and morbidity: prospective evidence from the Alameda County Study. Journal of Behavioural Medicine, 11, 1-13.

Knekt, P., Raitasalo, R., Heliovaara, M., Lehtinen, V., Pukkala, E., Teppo, L., Aromaa, A. (1996). Elevated lung cancer risk among persons with depressed mood. American Journal of Epidemiology, 144, 1096-1103.

(C) The International Journal of Indian Psychology, ISSN 2348-5396 (e)| ISSN: 2349-3429 (p) | 204 


\section{Predicting Cancer from Depression: A Systematic Review of Prospective Studies}

Lee, I. M. \& Paffenbarger, R. S. Jr. (1992). Body mass index and lung cancer risk [letter]. American Journal of Epidemiology, 136, 1417-1419.

McGee, R., Williams, S., \& Elwood, M. (1994). Depression and the development of cancer: a meta-analysis. Social Science and Medicine, 38, 187-192.

Miller, A. H., Spencer, R. L., McEwen, B. S., \& Stein, M. (1993). Depression, adrenal steroids, and the immune system. Annals of Medicine, 25, 481-487.

Moher, D., Liberati, A., Tetzlaff, J., \& Altman, D. (2009). Preferred reporting items for systematic reviews and meta-analyses: The PRISMA statement. PLoS Med 6, e1000097. doi:10.1371/journal.pmed.1000097.

Oerlemans, M. E., van den Akker, M., Schuurman, A. G., Kellen, E., \& Buntinx, F. (2007). A meta-analysis on depression and subsequent cancer risk. Clinical Practice and Epidemiology in Mental Health. 3, 29.

Penninx, B. W., Guralnik, J. M., Pahor, M., et al. (1998). Chronically depressed mood and cancer risk in older persons. Journal of National Cancer Institute, 90, 1888-1893.

Snow, H. L. (1893). Cancer and the cancer process. In A. L. Gross, J. J. Gallo, \& W. W. Eaton. (2010). Depression and cancer risk: 24 years of follow-up of the Baltimore Epidemiologic Catchment Area sample. Cancer Causes and Control, 21(2), 191-199. doi:10.1007/s10552-009-9449-99451.

Stein, M., Miller, A. H., Trestman, R. L. (1991). Depression, the immune system, and health and illness. Findings in search of meaning. Archives of General Psychiatry, 48, 171-177.

Wells, G., Shea, B., O'Connell, D., Petersen, J., Welch, V., Losos, M., \& Tugwell, P. Ottawa Scale (NOS) for assessing the quality of nonrandomized studies in meta-analyses. Ottawa: Ottawa Hospital Research Institute. Retrieved from http://www.ohri.ca/programs/clinical_epidemiology/oxford.asp.

Zonderman, A. B., Costa, P. T. Jr., McCrae, R. R. (1989). Depression as a risk for cancer morbidity and mortality in a nationally representative sample. Journal of American Medical Association, 262, 1191-1195.

How to cite this article: Damodaran D, Paul V (2017), Predicting Cancer from Depression: A Systematic Review of Prospective Studies, International Journal of Indian Psychology, Volume 4, Issue 2, No. 95, ISSN:2348-5396 (e), ISSN:2349-3429 (p), DIP:18.01.180/20170402, ISBN:978-1-365-84231-3 